Psychological Medicine, 1985, 15, 733-737

Printed in Great Britain

EDITORIAL

\title{
Female vulnerability to depression ${ }^{1}$
}

Evidence from several sources indicates that there is an increased risk of neuroses among women. This evidence derives from psychiatric in-patient samples (Cochrane \& Stopes-Roe, 1981), from general practice patients (Shepherd et al. 1966) and, most important, from community studies (Bebbington et al. 1981). Weissman \& Klerman (1977) have reviewed the evidence and argue that social factors contribute most to the sex difference in morbidity. Over the years a variety of social risk factors have been examined. These include, among others, maternal loss in childhood (Birtchnell, 1970), marital problems (Birtchnell \& Kennard, 1983), the stress of child rearing (Richman, 1976), and lack of employment opportunities (Warr \& Parry, 1982a). The evidence for some of these factors, such as parental loss (Tennant et al. 1981) or lack of employment (Warr \& Parry, 1982b), is far from conclusive. Indeed, it was on the basis that the above factors in their own right did not seem to correlate significantly with depression in women that Brown \& Harris (1978) invoked their 'vulnerability' model. They found that four 'vulnerability' factors (identified as 'maternal loss before the age of 15 years', 'three or more children under the age of 14 years', 'lack of marital intimacy' and 'lack of employment outside the home') contributed to depressive illness only when combined with a stressful life event ('provoking agent'). They argued that a synergistic (interaction) effect on the risk of depression was exerted by the combination of a 'vulnerability' factor and 'provoking' life event. The findings of their study have been discussed at some length in the literature (Tennant \& Bebbington, 1978; Bebbington et al. 1981; Brown \& Harris, 1980). The synergy identified by Brown \& Harris was, however, 'model' dependent, since the use of an alternative statistical model (i.e. multiplicative) failed to confirm the interaction (Tennant \& Bebbington, 1978). Brown \& Harris' additive model is less frequently preferred by statisticians (Everitt \& Smith, 1979; Costello, 1982).

Replications of Brown \& Harris' findings have now been attempted in a variety of studies. These include studies of social risk factors in hospital psychiatric patients, where the synergistic model is not assessed (Roy, 1978), to community studies of social risk factors, where synergy is assessed (Warr \& Parry, 1982a; Surtees et al. 1983). Others are perhaps more valid because they are community studies and use the same vulnerability factors as Brown and his colleagues (Costello, 1982; Solomon \& Bromet, 1982; Campbell et al. 1983; Cooke, 1981; Brown \& Prudo, 1981; Bebbington et al. 1984).

In the first of these 'replications' Roy (1978) found that 'loss of mother before the age of 11 years', 'three or more children at home under 14 years of age' and a 'lack of full time employment' were associated with depression in working-class women patients. For middle-class women patients only the lack of a confiding relationship was associated with depression. This study was a poor replication, since it was based on a depressed out-patient sample rather than community subjects. Furthermore, 'case' criteria and the definition of some variables were quite different from those of Brown and his colleagues. Perhaps most important, Roy did not test the vulnerability model (synergy) since life event stress had not been assessed.

Two community studies failed to demonstrate findings relating to a synergistic or vulnerability model for depression. In the first of these Warr \& Parry (1982 $b$ ) assessed risk factors for depression (using the Zung depression inventory) in working-class women with young children. The risk factors included employment status, attitude to home role, strain between home and work roles, social support, attitude to employment, and child care demands. The first 4 of these 6 factors were associated with depression. When, however, employment status was assessed in conjunction with each of the other risk factors, no interaction was found; each variable operated as an independent risk factor for depression. In the second study Surtees et al. (1983) studied Edinburgh women and

\footnotetext{
1 Address for correspondence: Associate Professor C. C. Tennant, Professorial Psychiatric Unit, Royal North Shore Hospital, St Leonards, NSW 2065, Australia.
} 
used three sets of 'case' criteria: PSE/Catego, SADS/RDC and Brown's Bedford College case criteria (Finlay-Jones et al. 1980). Demographic risk factors included age, marital status, social class and employment status. Regardless of the case criteria adopted, morbidity was more common in working-class 'unemployed' subjects. Similarly, morbidity was more common in women who were divorced, widowed or separated than in those who were married and than in single women. When multiplicative models were used, it was found that each risk factor had a direct effect on the disorder (irrespective of the case criteria), and no interaction (synergy) between them was identified. This study is not a close attempt at replication, since Brown \& Harris' (1978) 'vulnerability factors' and 'provoking agents' were not assessed.

Five community studies can be regarded as far more satisfactory attempts at replication, since they assess similar 'community' subjects, use similar definitions of 'vulnerability factors' and 'provoking agent', and adopt similar case criteria to those of Brown \& Harris (1978). In the first of these Costello (1982) assessed a community sample of 449 Canadian women. Like Brown and his colleagues, he used the PSE to assess psychiatric morbidity and Brown's method for determining the contextual threat of life events. Vulnerability factors were also defined in a fashion similar to that of Brown \& Harris (1978). No synergy was found between provoking agent and any of the vulnerability factors using a multiplicative model.

In the second study Solomon \& Bromet (1982) assessed a community sample of 435 North American women, all having at least one child under the age of 2 years. Depressive episodes were defined on the basis of RDC criteria derived from the SADS interview (Spitzer et al. 1978). Although all four of Brown's vulnerability factors were assessed, one of these ('loss of mother') was not included in the model, since none of the women suffering childhood maternal loss suffered from depressive illness. The 'provoking agent' (life stress) was assessed in two ways; first, by means of a brief, self-administered events inventory (whereby subjects were classified as under high or low stress); and, secondly, by reports of exposure or non-exposure to a severely threatening life event, namely the Three Mile Island (TMI) nuclear accident. Two thirds of the sample lived close to this facility. Those exposed to high stress (TMI nuclear accident) suffered from more depressive illness than those not so exposed. When a combination of the provoking agent (TMI accident) and each of two vulnerability factors (three children aged under 14 years, and no outside employment) was assessed by means of the 'additive' model, no interaction emerged. When the third 'vulnerability factor' (lack of intimacy) and the provoking agent (TMI accident) were assessed using an additive model, interaction (or synergy) was confirmed. When, however, the more usual multiplicative model was used, no interaction was found between any of the vulnerability factors and the provoking life stress. When life stress was assessed by the life events inventory, the earlier finding of an interaction between provoking life stress and 'lack of intimacy', using the additive model, was confirmed, but only in the women exposed to the TMI disaster. The multiplicative model did not confirm any interaction in this instance. The 'vulnerability' concept was thus demonstrated to be 'model' dependent, but only for one of the vulnerability factors, namely lack of intimacy.

In the third study Campbell et al. (1983) studied 110 working-class women with at least one child living at home. The PSE was used to assess psychiatric illness; Brown \& Harris' (1978) method was used to determine life stress, and three of their four vulnerability factors ('intimacy', 'three or more children at home' and 'lack of employment') were assessed. 'Maternal loss' was too infrequent to be included. While none of the vulnerability factors seemed to be associated with depression in their own right, other findings suggest that this may have been a type I error. When Brown \& Harris' (1978) additive model was used to assess the interaction between provoking agent (life stress) and each of the three vulnerability factors only one interaction emerged, namely that between life events and lack of intimacy. The alternative and more usual multiplicative model (Everitt \& Smith, 1979) was not used. A fourth unpublished study (Cooke, 1981), documented by Campbell et al. (1983), assessed a community sample of subjects and found no interaction between life events, assessed by means of Paykel et al.'s measure (1969), and Brown \& Harris' vulnerability factors. It appeared that each factor operated as an independent risk factor for psychiatric morbidity.

In the fifth study Brown \& Prudo (1981) attempted to replicate their South London findings in 
a sample of Hebridean women. Only one of their four vulnerability factors (three or more children under 14 years) was significantly associated with depression. When 'lack of churchgoing' was substituted for one of the original vulnerability factors (loss of mother before age of 11 years), they found that the risk of depression caused by life events increased in proportion to the number of vulnerability factors. They did not find, however, that there was any interaction between life events, the vulnerability factors and depression; their original 'vulnerability' model was thus not replicated.

Finally, the sixth and closest of all the replicative studies is that of Bebbington et al. (1984) who not only employed identical criteria for defining cases, provoking life stress and vulnerability factors, but also used subjects from the same Camberwell community in South London. Two procedures were used to define cases: (1) the PSE Index of Definition (ID) (Wing et al. 1974); and (2) the algorithm of Finlay-Jones et al. (1980), which in essence replicates Brown's case criteria. Since Bebbington et al.'s study involved two interviews of subjects one month apart, both these algorithms were applied to both sets of interview data, thus producing four determinations of 'caseness'. The relationship of each of the four 'vulnerability' factors was assessed in relationship to these four 'case' definitions, with the exception of intimacy, which was assessed in relation only to the two 'case' definitions derived from the second interview. The 'intimacy' data were collected only at the second interview, whereas the other data were collected at the first interview. When the simple associations were assessed, 'loss of mother' bore no relation to any index of 'caseness'; 'unemployment' was associated with the ID index at first interview only; 'three children under the age of 15 years' was associated with the ID index at second interview alone; and 'lack of intimacy' was associated with both the ID and the indices of 'caseness' of Finlay-Jones $e t$ al. (1980) at second interview.

When the vulnerability model was assessed by looking for conditional effects using an additive model like that of Brown \& Harris there was no evidence of synergy between any one of the 'vulnerability factors' and the 'provoking agent' (life events). Brown \& Harris' vulnerability model was therefore not replicated. Brown's model, however, is an attempt to explain the higher risk of disorder observed in working-class women with young children and this was replicated by Bebbington $e t$ al. (1984). In both studies this was largely attributed to the presence of 'provoking' life stress in that group of women.

What emerges from these replications is that interactions between some 'risk factors' do occur, but not necessarily as proposed by Brown \& Harris (1978). First, both Brown \& Harris (1978) and Bebbington et al. (1984) found some evidence of an interaction between lower social class, life event stress and morbidity. Secondly, three studies (Brown \& Harris, 1978; Campbell et al. 1983; Solomon \& Bromet, 1982) found an interaction between 'lack of intimacy', life events and psychological disorder in women. This latter evidence lends some support to one part of Brown \& Harris' vulnerability model.

The finding of this latter interaction is indirectly supported by other empirical data, namely those from studies of the stress-buffering effect of social supports. However, even this body of findings is not consistent (see reviews by Dean \& Lin, 1977; Thoits, 1982; Henderson, 1983). Some of the studies are retrospective, others are prospective; they have usually involved both males and females. Of the first group of twelve retrospective studies, only four appear to show any buffering effect ('interaction') between social supports and life stress on psychological illness (Nuckolls et al. 1972; House \& Wells, 1978; Paykel et al. 1980; La Rocco et al. 1980), while eight show no such buffering effect (Andrews et al. 1978; Aneshensel \& Stone, 1982; Henderson et al. 1981; Lin et al. 1979; Frydman, 1981; Williams et al. 1981; La Rocco \& Jones, 1978; Pinneau, 1975). The causal interpretations of these retrospective studies are, however, severely limited.

Four prospective studies provide the most substantial evidence concerning a causal association (Eaton, 1978; Warheit, 1979; Gore, 1978; Henderson et al. 1981). In the first of these Eaton (1978) found that only two of his eight indices of social support showed an interaction with life stress in producing psychological disorder. Similarly, Warheit (1979) found some interaction effects but noted that life stress and social supports contributed a trivial proportion of the variance of disorder $(3 \%$ and $4 \%$ respectively), while the initial depression scores made substantial contributions thereto 
$(45 \%)$. He argued that these findings highlighted the importance of depressive traits in the aetiology of minor depressive episodes. The third prospective study (Gore, 1978) showed no stress buffering of social supports in subjects recently made occupationally redundant. Henderson et al.'s (1981) impressive study also failed to confirm any interaction. These workers found that personality factors accounted for nearly $70 \%$ of the variance in psychological morbidity, while life stress made a trivial but independent contribution to disorder. The objective assessment of social relationships had no significant effect on morbidity and did not interact with life stress in contributing to its genesis.

In summary, Brown \& Harris' vulnerability model for depression has not been replicated. To some extent failures of replication may be due to sample differences, different definition of some variables and differences in statistics used (additive versus multiplicative models). In the closest replication studies Bebbington et al. (1984) confirmed that working-class women are at a greater risk of disorders caused by life stress, but that Brown's four specific 'vulnerability' factors for this group were not supported. While some synergy has been suggested between life stress and lack of intimacy (poor social supports etc.) in some other studies, this finding is poorly supported in those studies specifically assessing the stress buffering effect of social supports. At present, the evidence suggests that social risk factors act independently of each other and, even then, that these risk factors may vary considerably from one population to another. There is, however, room for future research on the clarification of the concepts of 'vulnerability factors' and 'provoking agents'.

CHRISTOPHER TENNANT

\section{REFERENCES}

Andrews, G., Tennant, C., Hewson, D. M., \& Vaillant, G. E. (1978). Life event stress, social support, coping style and risk of psychological impairment. Journal of Nervous and Mental Disease 166, 307-316.

Aneshensel, C. S. \& Stone, J. D. (1982). Stress and depression. Archives of General Psychiatry 39, 1392-1396.

Bebbington, P. E., Hurry, J., Tennant, C., Sturt, E. \& Wing, J. K. (1981). The epidemiology of mental disorders in Camberwell. Psychological Medicine 11, 561-580.

Bebbington, P. E., Sturt, E., Tennant, C. \& Hurry, J. (1984). Misfortune and resilience: a community study of women. Psychological Medicine 14, 347-363.

Birtchnell, J. (1970). Depression in relation to early and recent parent death. British Journal of Psychiatry 116, 299-306.

Birtchnell, J. \& Kennard, J. (1983). Marriage and mental illness. British Journal of Psychiatry 142, 193-198.

Brown, G. W. \& Harris, T. (1978). The Social Origins of Depression. Tavistock: London.

Brown, G. W.\& Harris, T. (1980). Causes and logic in epidemiological psychiatry 4. Further comments on the vulnerability model. British Journal of Psychiatry 137, 584-585.

Brown, G. W. \& Prudo, R. (1981). Psychiatric disorder in a rural and an urban population: 1. Aetiology of depression. Psychological Medicine 11, 581-599.

Campbell, E. A., Cope, S. J. \& Teasdale, J. D. (1983). Social factors and affective disorder: an investigation of Brown and Harris' model. British Journal of Psychiatry 143, 548-553.

Cochrane, R. \& Stopes-Roe, M. (1981). Women, marriage, employment and mental health. British Journal of Psychiatry 139, 373-381.

Cooke, D. (1981). Life events, depression and vulnerability factors: a theoretical and empirical evaluation. Paper presented at British Psychological Society Annual Conference.

Costello, C. G. (1982). Social factors associated with depression: a retrospective community study. Psychological Medicine 12, 329-339.

Dean, A. \& Lin, N. (1977). The stress buffering role of social support. Journal of Nervous and Mental Disease 165(6), 403-417.

Eaton, W. E. (1978). Life events, social supports, and psychiatric symptoms: a re-analysis of the New Haven data. Journal of Health and Social Behaviour 19, 230-234.
Everitt, B. S. \& Smith, A. M. (1979). Interactions in contingency tables: a brief discussion of alternative definitions. Psychological Medicine 9, 581-583.

Finlay-Jones, R., Brown, G. W., Duncan-Jones, P., Harris, T., Murphy, E. \& Prudo, R. (1980). Depression and anxiety in the community: replicating the diagnosis of a case. Psychological Medicine 10, 445-454.

Frydman, M. I. (1981). Social support, life events and psychiatric symptoms: a study of direct, conditional and interaction effects. Social Psychiatry 16, 69-78.

Gore, S. (1978). The effect of social support in moderating the health consequences of unemployment. Journal of Health and Social Behaviour 19, 157-165.

Henderson, A.S. (1983). Vulnerability to depression: the lack of social support does not cause depression. In The Origins of Depression: Current Concepts and Approaches (ed. J. Angst), pp. 107-119. Springer-Verlag: Berlin.

Henderson, A. S., Byme, D. G. \& Duncan-Jones, P. (1981). Neurosis and the Social Environment. Academic Press: Sydney.

House, J. S. \& Wells, J. A. (1978). Occupational stress, social support, and health. In Reducing Occupational Stress (ed. A. McLean, G. Black and M. Colligan), pp. 8-29. Proceedings of a Conference USDHEW (NIOSH) Publication No. 78-140. Department of Health, Education and Welfare: Washington, D.C.

La Rocco, J. M. \& Jones, A. P. (1978). Co-workers and leader support as moderators of stress-strain relationships in work situations. Journal of Applied Psychology 63, 629-634.

La Rocco, J. M., House, J. S. \& French, J. R. P. Jr (1980). Social support, occupational stress and health. Journal of Health and Social Behaviour 21, 202-218.

Lin, N., Ensel, W. M., Simeone, R. S. \& Kuo, W. (1979). Social support, stressful life events, and illness: a model and an empirical test. Journal of Heallh and Social Behaviour 20, 108-119.

Nuckolls, K. B., Cassel, J. \& Kaplan, B. H. (1972). Psychological assets, life crisis and the prognosis of pregnancy. American Journal of Epidemiology 95, 431-441.

Paykel, E. S., Myers, J. K., Dienelt, M. N., Klerman, G. L., Lindenthal, J. J. \& Pepper, M.P. (1969). Life events and depression: a controlled study. Archives of General Psychiatry 21, 753-760.

Paykel, E. S., Ems, E. M., Fletcher, J. \& Ratsaby, E. S. (1980). Life 
events and social support in puerperal depression. British Journal of Psychiatry 136, 339-346.

Pinneau, S. R. Jr (1975). Effects of social support on psychological and physiological strains. Ph.D. Dissertation: University of Michigan

Richman, N. (1976). Depression in mothers of preschool children. Journal of Child Psychology and Psychiatry 17, 75-78.

Roy, A. (1978). Vulnerability factors and depression in women. British Journal of Psychiatry 133, 106-110.

Shepherd, M., Cooper, B., Brown, A. C. \& Kalton, G. W. (1966). Psychiatric Illness in General Practice. Oxford University Press: London.

Solomon, Z. \& Bromet, E. (1982). The role of social factors in affective disorder: an assessment of the vulnerability model of Brown and his colleagues. Psychological Medicine 12, 123-130.

Spitzer, R., Endicott, J. \& Robins, E. (1978). Research diagnostic criteria : rationale and reliability. Archives of General Psychiatry 35, 773-782.

Surtees, P. G., Dean, C., Ingham, J. G., Kreitman, N. B., Miller, P. Mc. C. \& Sashidharan, S. P. (1983). Psychiatric disorder in women from an Edinburgh Community: associations with demographic factors. British Journal of Psychiatry 142, 238-246.

Tennant, C. \& Bebbington, P. (1978). The social causation of depression: a critique of the work of Brown and his colleagues. Psychological Medicine 8, 565-575.
Tennant, C., Smith, A., Bebbington, P. \& Hurry, J. (1981). Parental loss in childhood, adult psychiatric impairment and contact with psychiatric services. Archives of General Psychiatry 38, 309-314.

Thoits, P. A. (1982). Conceptual, methodological, and theoretical problems in studying social support as a buffer against life stress. Journal of Health and Social Behaviour 23, 145-159.

Warheit, G. J. (1979). Life events, coping, stress, and depressive symptomatology. American Journal of Psychiatry 136, 502-507.

Warr, P. \& Parry, G. (1982a). Depressed mood in working class mothers with and without paid employment. Social Psychiairy 17 161-165.

Warr, P. \& Parry, G. (1982b). Paid employment and women's psychological well-being. Psychological Bulletin 91, 498-516.

Weissman, M. M. \& Klerman, G. L. (1977). Sex differences and the epidemiology of depression. Archives of General Psychiatry 34, 98-111.

Williams, A. W., Ware, J. E. \& Donald, C. A. (1981). A model of mental health, life events, and social supports applicable to general populations. Journal of Health and Social Behaviour 22, 321-336.

Wing, J. K., Cooper, J. E. \& Sartorius, N. (1974). Measurement and Classification of Psychiatric Symptoms. Cambridge University Press: Cambridge. 